\title{
Costs prompt West German second thoughts on space programme
}

\section{Munich}

A PREDICTED doubling of the costs for Hermes, Columbus and Ariane - the pillars of Europe's space programme - has created confusion and doubt in the West German government. It is now unclear whether West Germany will continue to support the projects, administered by the Paris-based European Space Agency.

The three projects will cost about DM30,000 million over the next ten years, of which West Germany is to pay almost one-third. A decision on participation is due when the Bundestag reconvenes in the autumn.

West Germany doubled its 1987 budget for the three projects in late June, lending credence to the idea that support would continue at this higher level. But there was speculation during the first week of July that the Bonn government would request a five-year delay in the Hermes space shuttle project. Such a move would seem to favour the development of the two alternative European shuttles, the British Hotol and the West German Sänger. But this will anger France, the strongest advocates of Hermes.

The claim that West Germany would call for a delay in the Hermes project was denied by an official in the Ministry for Research and Technology (BMFT). Nevertheless, extending the programmes over a longer time-span is one of the most reasonable suggestions for dealing with the massive cost increase. BMFT cannot provide the extra funds, and the West German Finance Ministry is presumed to be reluctant to open its pursestrings.

The challenge to Hermes comes from powerful figures such as Wolf-Michael Catenhusen, chairman of the Research and Technology Committee of the Bundestag. Catenhusen disapproves of Hermes because it is "just a small version of the US space shuttle" which will be long outdated by the time it is put into service in 1995. By this logic, a delay in Hermes could well mean its end.

Catenhusen, a Social Democrat (SPD), makes more general charges, complaining that the ruling conservative coalition has approved expensive space projects without having a comprehensive policy. BMFT's proposal on 24 June to establish a West German space agency seems a tacit acknowledgement that the government has indeed been weak in this regard.

But SPD science spokesman Josef Vosen continues to support German participation in Hermes as well as Columbus, the European section of the manned space station to be built by the United States. Vosen fears the political consequences of pulling out of either Hermes or
Columbus. He accused the supporters of Sänger as an alternative to Hermes of "living in a dream world".

Vosen supported his arguments by citing the low level of support for the space programme in West Germany: \$14 per inhabitant a year compared with $\$ 22$ in France and $\$ 100$ in the United States. Previous cooperative projects such as Spacelab, financed by West Germany, used for two missions, and then given to the United States, are proof, he says, that Europe needs an independent space programme. Spacelab was a case, Vosen said, where "We [and the US] ate the cake together, but we paid for it ourselves."

West German participation in the European space programme is ultimately a question of political will. Arguments that West Germans spend too little on space flight seem unlikely to succeed with the electorate. One more failure of the Ariane rocket could create insurmountable opposition to any new initiatives, leaving politicians in the difficult position of choosing whether to please their allies or their constituents.

\section{Lakes on the way to recovery from long-term acidification abuse}

\section{London}

BRITISH and Scandinavian scientists have discovered the first indications of recovery in some lakes acidified by sulphur emissions.

Scientists working in the Surface Water Acidification Programme of the Royal Society of London, the Royal Swedish Academy of Sciences and the Norwegian Academy of Science and Letters have just published the results of their first three years of work, after a conference last week in Bergen. Studies of diatoms in lake

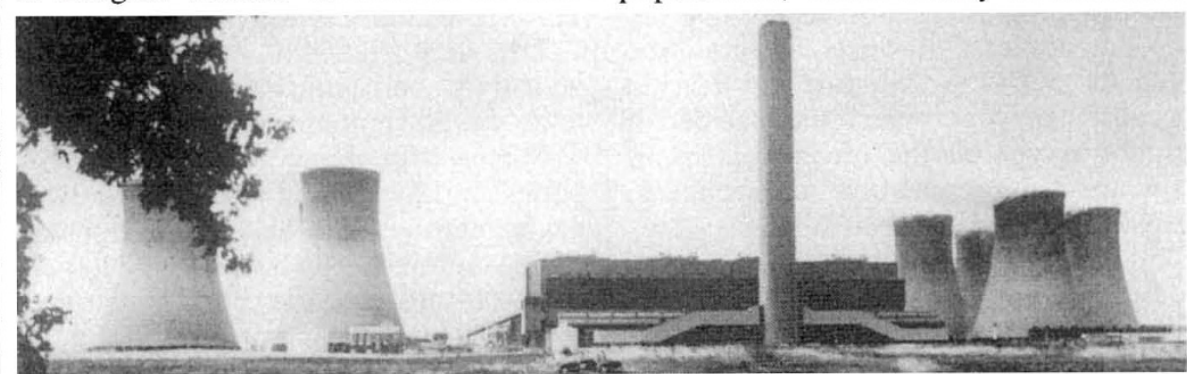

The 650-foot multiflue chimney with cooling towers at the CEGB's Fiddler's Ferry power station. sediments revealed progressive acidification of lakes in Norway, Sweden and Scotland from 1850 until about 1970 , with a slight decrease since 1975 when sulphur emissions from Britain began to decline.

"There is no doubt that we have to reduce sulphur emissions to reduce acidification", said the director of the programme, Sir John Mason of the University of London's Imperial College. "We still have some questions to answer on how long it will take to show any effect, and that depends on the soil type and other factors."

The research shows a strong correlation between areas of high acidic deposition, acidified surface waters and the decline of fish populations. Measurements of $p \mathrm{H}$, aluminium and calcium in surface water will give an indication of whether fish will live or die, the scientists have concluded.

The role of forests in water acidification has also been examined by the pro- gramme. "Planting forests has changed the acidity of waters in all three countries we studied", Mason says.

Forests contribute to acidification by the filtering action of their needles, which capture mist and fog particles; by taking up magnesium and calcium in their roots and replacing it with hydrogen; and by altering drainage patterns when planted in previously non-forested areas.

What the scientists call "short sharp episodes" can have a lethal effect on fish populations; when acidity is increased quickly due to snowmelt or storms, the fish cannot tolerate the effect. "This means measurements must be made continuously, which is an important discovery", Mason notes. He praises the level of cooperation among the scientists.

Britain's Central Electricity Generating Board, which is funding the five-year programme, says the results so far are consistent with earlier information which led it to a decision to install flue gas desulphurization (FGD) at three of its 40 power stations. The first FGD will be retrofitted at the Drax power station in Yorkshire by 1993, with planning work still going on for the other two units.

Mason says that "the fact that the scientists say we must remove the sulphur will underpin the CEGB policy."

Kathy Johnston

This is the first issue of Nature to be printed in Japan. 